\title{
A Three-Level Three-port Bidirectional DC-DC Converter
}

\author{
Ganjavi, Amir; Ghoreishy, Hoda; Ahmad, Ahmad Ale; Zhagn, Zhe
}

Published in:

Proceedings of 2018 IEEE International Power Electronics and Application Conference and Exposition

Link to article, DOI:

10.1109/PEAC.2018.8590338

Publication date:

2018

Document Version

Peer reviewed version

Link back to DTU Orbit

Citation (APA):

Ganjavi, A., Ghoreishy, H., Ahmad, A. A., \& Zhagn, Z. (2018). A Three-Level Three-port Bidirectional DC-DC Converter. In Proceedings of 2018 IEEE International Power Electronics and Application Conference and Exposition (pp. 1-4). IEEE. https://doi.org/10.1109/PEAC.2018.8590338

\section{General rights}

Copyright and moral rights for the publications made accessible in the public portal are retained by the authors and/or other copyright owners and it is a condition of accessing publications that users recognise and abide by the legal requirements associated with these rights.

- Users may download and print one copy of any publication from the public portal for the purpose of private study or research.

- You may not further distribute the material or use it for any profit-making activity or commercial gain

- You may freely distribute the URL identifying the publication in the public portal 


\section{A Three-Level Three-port Bidirectional DC-DC Converter}

\author{
Amir Ganjavi \\ Department of Electrical and Computer \\ Engineering \\ Babol Noshirvani University of \\ Technology \\ Babol, Iran \\ amirganjavy@gmail.com \\ Zhe Zhang \\ Department of Electrical Engineering \\ Technical University of Denmark \\ Kongens Lyngby, Denmark \\ zz@elektro.dtu.dk
}

\author{
Hoda Ghoreishy \\ Department of Electrical and Computer \\ Engineering \\ Babol Noshirvani University of \\ Technology \\ Babol, Iran \\ ghoreishy@nit.ac.ir
}

\author{
Ahmad Ale Ahmad \\ Department of Electrical and Computer \\ Engineering \\ Babol Noshirvani University of \\ Technology \\ Babol, Iran \\ a.ahmad@nit.ac.ir
}

\begin{abstract}
This Paper proposes a novel three-level, threeport, bidirectional dc-de converter (TLTPBC). Through the bidirectional battery port, the TLTPBC guarantees the continuous flow of energy to the load when the system is deprived of the input source during faults. Owing to reduction of voltage stress across semiconductor devices, the proposed converter is appropriate for medium and high voltage applications, such as transportation systems, residential and office buildings. Moreover, the size of the passive components is reduced which is the inherent advantage of the three-level structures. The results demonstrate the proposed merits of the converter, and verify that the output voltage is well regulated both in presence and absence of the input source.
\end{abstract}

Keywords- Bidirectional, three-level three-port bidirectional dc-de converter (TLTPBC), dc-dc converter, multiport converter, three-level dc-dc converter.

\section{INTRODUCTION}

Bidirectional dc-dc converters have been increasingly popular in industry because of the requirements of battery based energy storage systems. In addition, utilizing different types of renewable energy sources as interfaces for providing energy to load seems to be a bright idea. Therefore, bidirectional multiport dc-dc converters (BMC) can play an important role to share different energy sources and storage devices of different characteristics [1]. However, in medium and high voltage applications, the voltage stress across semiconductor devices is a big challenge for BMCs. High voltage stress across switches and diodes not only imposes high costs on the system but also reduce the overall efficiency [2]-[4].

Reference [2] proposes a non-isolated multiport threelevel dc-dc converter. The converter's topology is achieved through the combination of multiport and three-level dc-dc converters. However, the converter has a unidirectional control structure which is not capable of handling energy management when using a battery in one of the ports. In [5], a BMC is proposed which is derived from the triangular modular multilevel dc-dc converter. In this converter, the switches' voltage stress is shared amongst the levels. However, the converter suffers from a complex control system.

Reference [6] proposes a three port converter composed of a source, a bidirectional battery port, and an isolated load port. The converter's topology is made up of one middle branched added to the traditional half-bridge converter.

This paper proposes a new non-isolated, three-level three-port, bidirectional dc-dc converter (TLTPBC) with a straightforward control system. Reduced voltage stress across switches and diodes, and reduced passive components size are among the main merits of the proposed converter. The TLTPBC is enable to provide energy for the load during the power failure through its bidirectional battery port. Also, with reduced voltage stress across semiconductor devices, the TLTPBC is an attractive option for medium and high voltage applications, such as transportation systems, residential and office buildings, etc.

This paper is organized as follows: In section II, the topology structure and operation principles of the proposed converter are described. This section also explains the threelevel control strategy of the proposed converter. Section III provides the simulation results of the designed example to verify the theoretical analysis. Finally, section IV concludes the paper.

\section{OPERATING PRINCIPLE}

\section{A. Topology of the Proposed Converter}

The proposed TLTPBC has been shown in Fig. 1 where $v_{i n}$ is the input voltage, $v_{b}$ is the battery voltage and $v_{o}$ is the step-up output voltage. Two identical capacitors ( $C_{11}$ and $\left.C_{12}\right)$ connected in series are the output filters. Main components of the converters are: $S_{1}, S_{2}, S_{3}$, and $S_{4}$ switches with antiparallel diodes and $D_{11}$ and $D_{12}$ power diodes.

\section{B. Operating Modes}

For the TLTPBC, two operating modes have been assigned. Fig. 2 shows the operating modes of the TLTPBC in presence and absence of the input source. In mode I (charging mode), as shown in Fig. 2 (a), the input source provides energy for both the battery and the load; thus, the battery is charging. In mode II (discharging mode), as shown in Fig. 2 (b), the system is deprived of input source due to the faults, power failure, etc., so the battery provides energy to the load; in other words, the battery is discharging. 


\section{Control Strategy}

As previously mentioned, the three-level control of the proposed bidirectional multiport converter makes the voltage stress across semiconductor devices reduce, and causes the passive components size to shrink. Fig. 3 shows the block diagram of the three-level control strategy for the TLTPBC. According to Fig. 3, the converter is controlled through two simple proportional-integral (PI) compensators.

The output voltage $v_{o}$ and the battery state of the charge $v_{b}$, should be controlled. Achieving this goal, a closed loop control strategy shown in Fig. 4 . is realized. $V_{o, r e f}$ and $V_{b, r e f}$ are the output voltage and battery voltage reference values, respectively. The input variables to $\mathrm{PI}_{1}$ and $\mathrm{PI}_{2}$ blocks (error signals) will be converted to $d_{P I 1}$ and $d_{P I 2}$, respectively. $d_{p I 1}$ composes the duty-cycle of the switches $S_{2}$ and $S_{3}$, and $d_{p I 2}$ composes the duty-cycle of the switches $S_{1}$ and $S_{4}$.

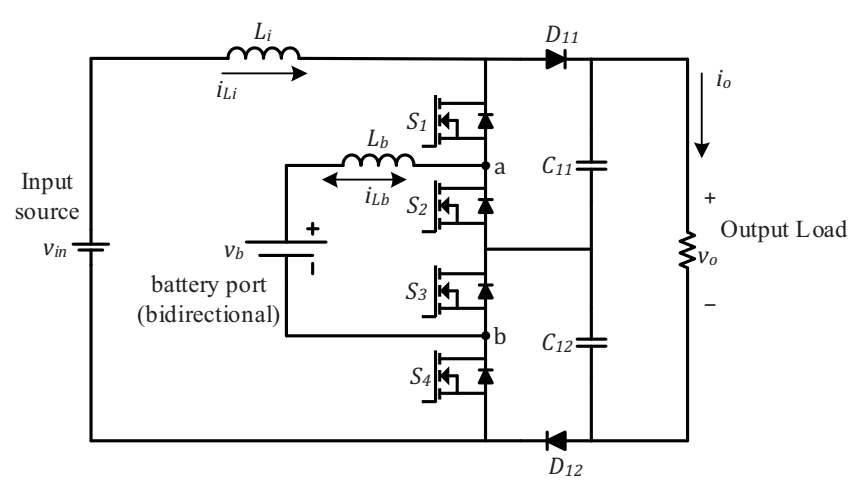

Fig. 1. The proposed TLTPBC.

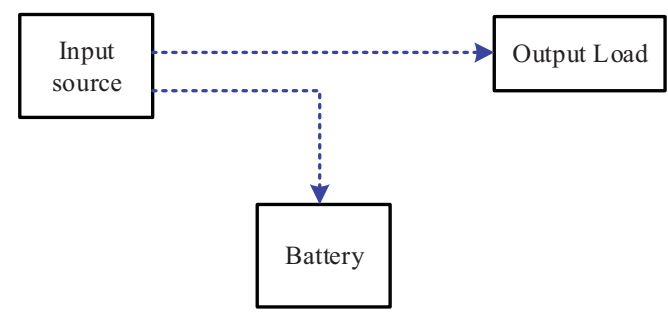

(a)
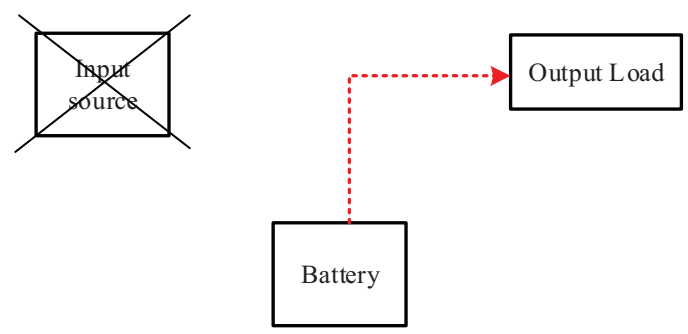

(b)

Fig. 2. Operating modes of the TLTPBC: (a) Mode I (charging mode), (b) Mode II (discharging mode).
The utilized modulation technique is PS-PWM with sawtooth carriers. The duty-cycles of $S_{1}$ and $S_{4}$ control signals are the same $\left(d_{s 1}=d_{s 4}=d_{1}\right)$ but 180 degree phase-shifted. In the same way, the control signals of $S_{2}$ and $S_{3}$ have the same duty-cycles $\left(d_{s 2}=d_{s 3}=d_{2}\right)$ and are 180 degree phase-shifted. It should be noted the aim of the control of $v_{b}$ is to control the voltage around the battery's nominal voltage. Therefore, that is the energy management system (EMS) which determines the reference value of $V_{b, r e f}$ considering into which operating mode the TLTPBC is working. If the battery is charging (Mode I), the EMS assigns a value more than the nominal voltage of the battery; and when the battery is discharging, the EMS assigns a value less than the nominal voltage of the battery. That is because during the battery's charging mode, the battery's voltage is more than its nominal voltage and vice versa during the discharging mode.

\section{VERIFICATION}

In order to verify the theoretical analysis, a TLTPBC has been designed. The converter parameters for a design example have been shown in Table I.

\section{A. Charging Mode Simulation Results}

Fig. 5 shows the TLTPBC behavior in steady state while operating in Mode I (charging mode). In Fig. 5 (a), it is shown that $V_{o}$ is well regulated at its predefined value of 125 $\mathrm{V}$. Moreover, it can be seen that the voltage stress across the switches and diodes is about $62.5 \mathrm{~V}$ which is half of the output voltage. Also, it can be seen that the effective ripple frequency of output voltage $v_{o}$ and unfiltered battery port voltage $V_{a b}$ is twice the switching frequency.

In Fig. 5 (b), it is also seen that the ripple frequencies of the inductors currents are twice as much as the switching frequency. This will cause the reduction of the passive components size that is an inherent feature of the three-level structure. In addition, a 180 degree phase shift between the control signals of $S_{2}$ and $S_{3}$ can be seen from the figure.

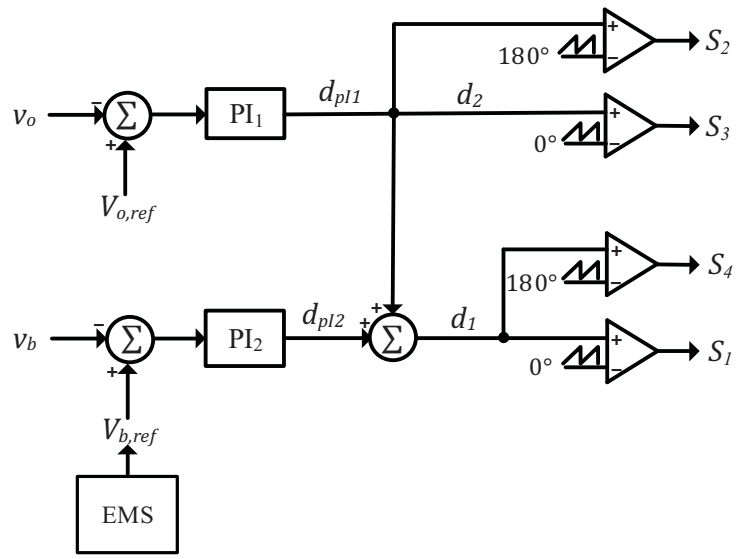

Fig. 4. Block diagram of the closed-loop control system. 
TABLE I. DESIGN PARAMETERS OF THE TLTPBC

\begin{tabular}{|c|c|}
\hline Parameter & Value \\
\hline Input Voltage $\left(V_{\text {in }}\right)$ & $60 \mathrm{~V}$ \\
\hline Output Voltage $\left(V_{o}\right)$ & $125 \mathrm{~V}$ \\
\hline Battery Nominal Voltage $\left(V_{b}\right)$ & $36 \mathrm{~V}$ \\
\hline Resistive Load $\left(R_{o}\right)$ & $65 \Omega$ \\
\hline Input Inductor $\left(L_{i}\right)$ & $401 \mu \mathrm{H}$ \\
\hline Output Capacitor $\left(C_{11}=C_{12}\right)$ & $30 \mu \mathrm{F}$ \\
\hline Battery Port Inductor $\left(L_{b}\right)$ & $740 \mu \mathrm{H}$ \\
\hline Switching Frequency $\left(f_{S W}\right)$ & $20 \mathrm{KHz}$ \\
\hline
\end{tabular}

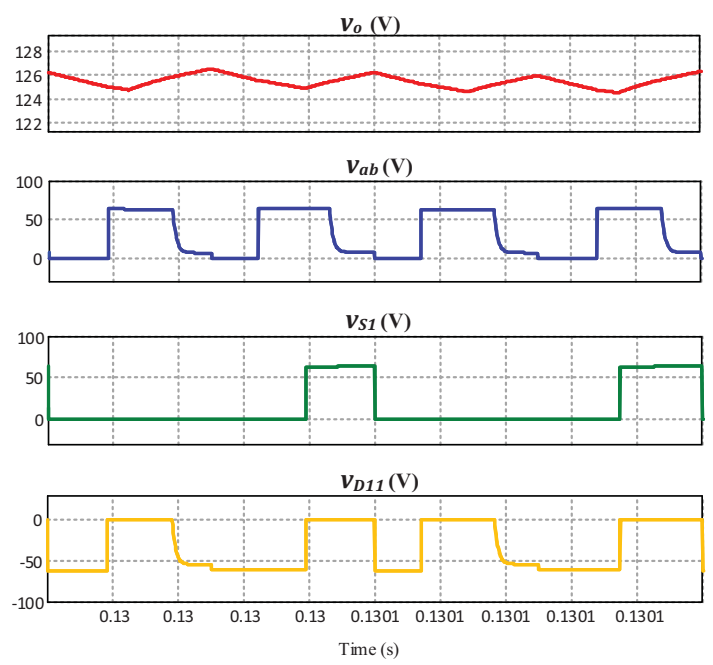

(a)
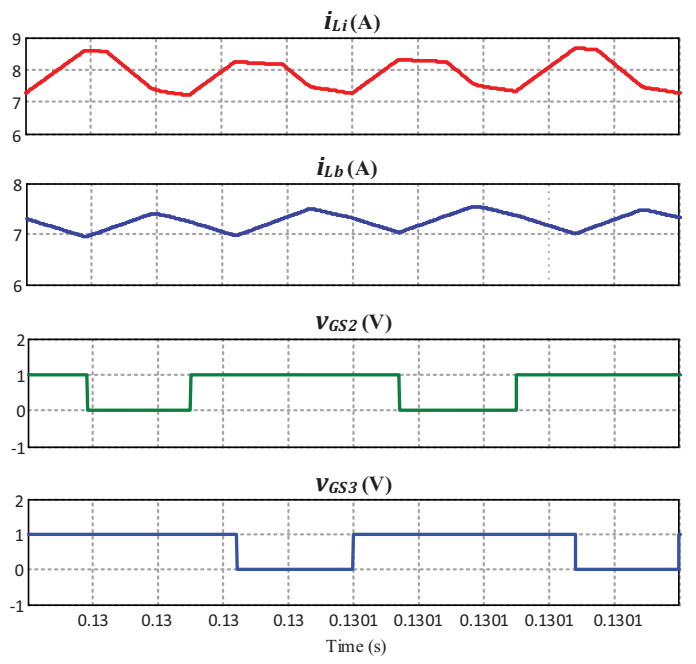

(b)

Fig. 5. Steady-state simulation waveforms of the TLTPBC when the battery is charging in Mode I $\left(V_{\text {in }}=60 \mathrm{~V}, V_{0}=125, R_{0}=65\right)$. (a) Output voltage, unfiltered battery port voltage $v_{a b}$, voltage across $S_{1}$ and $D_{11}$. (b) Inductors currents and the control signals of $S_{2}$ and $S_{3}$.

\section{B. Discharging Mode Simulation Results}

Fig. 6 shows the TLTPBC behavior in steady state while operating in Mode II (discharging mode). In Fig. 6 (a), it is shown that the output voltage is well regulated at its predefined value. According to Figs. 6 (a) and (b), it is seen that in mode II, the voltage stress across $S_{1}$ and $S_{4}$ is only about one-third of the output voltage, and for the other switches and diodes the voltage stress is half of the output voltage; this will reduce the cost of the system and enhance the overall efficiency at the same time. Moreover, it can be seen that the ripple frequencies of $v_{o}, v_{a b}$, and $i_{L b}$ are twice as much as the switching frequency, reducing the size of inductors and capacitors.

\section{Experimental Results}

Fig. 7 shows the steady-state experimental waveforms of the TLTPBC when the battery is charging. In Fig. 7, it is shown that the output voltage is well regulated at $V_{o}=125 \mathrm{~V}$. Also, it is seen that the frequency of the battery's inductor current is twice the switching frequency. Moreover, it is proved that the voltage stress across the semiconductor devices is half as much as the output voltage.
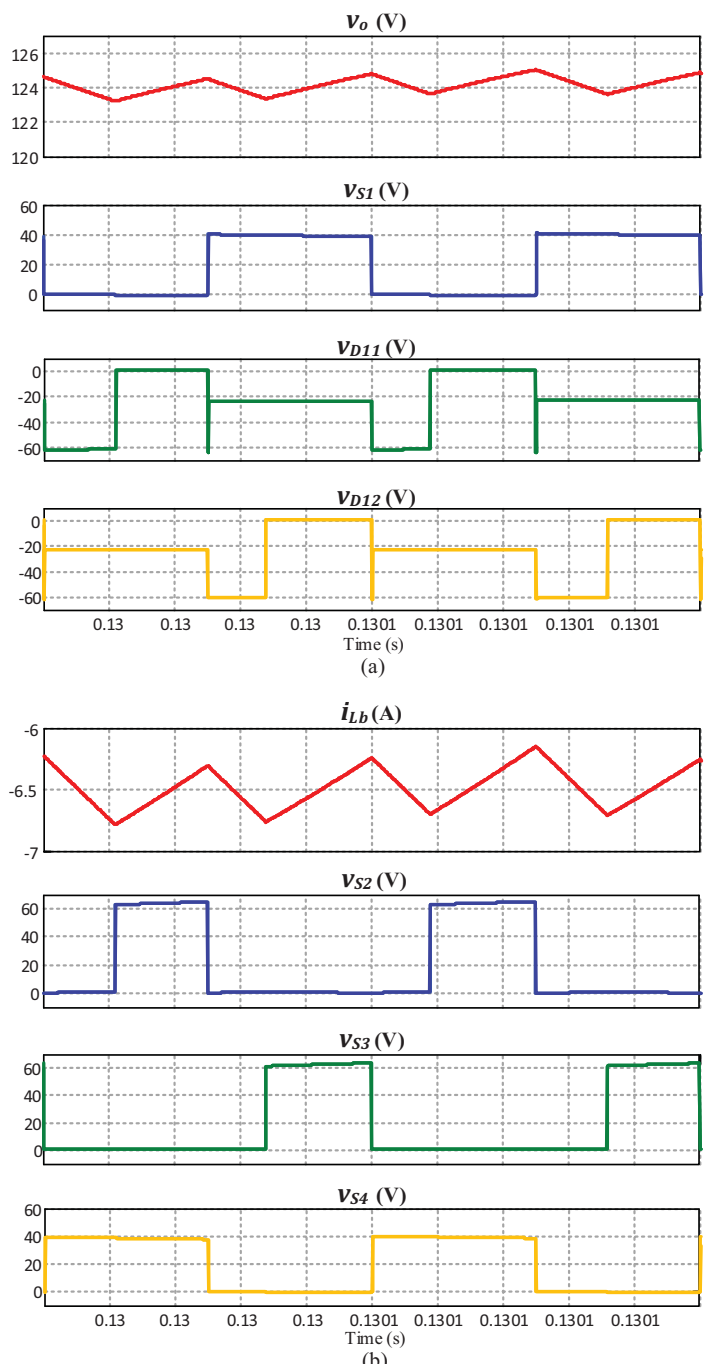

(b)

Fig. 6. Steady-state simulation waveforms of the TLTPBC when the battery is discharging in Mode II $\left(V_{\text {in }}=60 \mathrm{~V}, V_{0}=125, R_{0}=65\right)$. (a) Output voltage, voltage across $S_{1}, D_{11}$, and $D_{12}$. (b) The battery's inductor current, voltage across $S_{2}, S_{3}$, and $S_{4}$.

\section{CONCLUSION}

This paper proposed a novel non-isolated TLTPBC which guarantees the continuous flow of energy to the load when the system is deprived of the input source through a bidirectional battery port. The results proved that with the straightforward PWM control, the boost output is well regulated both during the charging and discharging mode. 
Also, due to the intrinsic feature of three-level structure, the maximum voltage stress across the semiconductor devices only half as much as the output voltage, making the converter attractive for medium and high voltage applications. The reduced voltage stress across semiconductor devices reduce the system cost and improves the efficiency. Moreover, the passive elements size shrank due to the fact that the ripple frequencies of the output voltage and inductors are twice as much as the switching frequency.

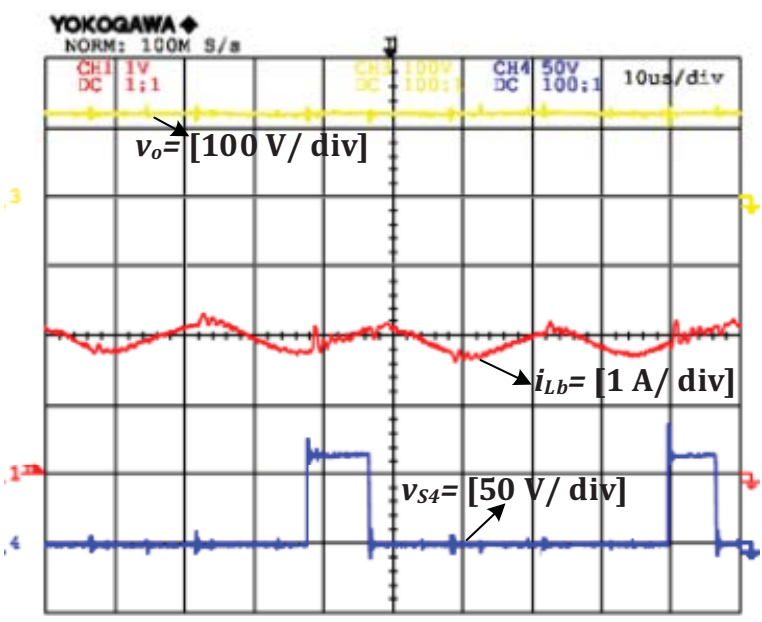

(a)

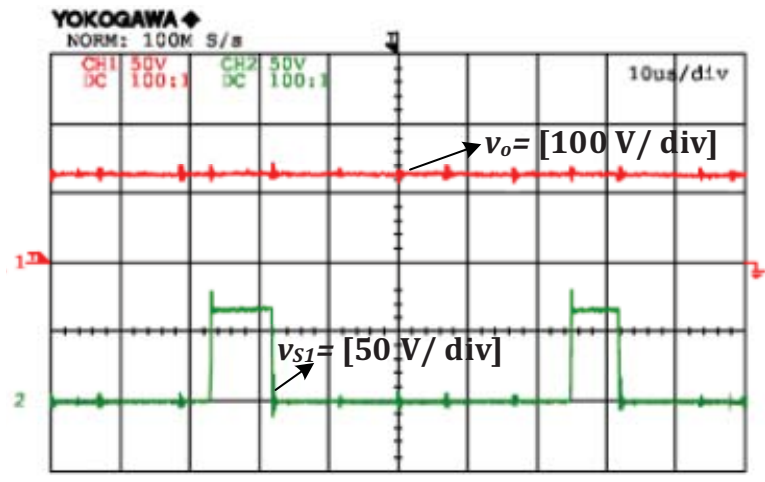

(b)

Fig. 7. Steady-state experimental waveforms of the TLTPBC when the battery is charging in Mode I $\left(V_{\text {in }}=60 \mathrm{~V}, V_{0}=125, R_{0}=65\right)$. (a) Output voltage, the battery's inductor current, voltage across $S_{4}$. (b) Output voltage, voltage across $S_{1}$.

\section{REFERENCES}

[1] C. Zhao, S. D. Round, and J. W. Kolar "An isolated three-port bidirectional DC-DC converter with decoupled power flow management," IEEE Trans. Power Electron., vol. 23, no. 5, pp. 2443 -2453 , Sep. 2008.

[2] A. Ganjavi, H. Ghoreishy, and A. A. Ahmad, "A novel single-input dual-output three-level DC-DC converter," IEEE Trans. Ind. Electron., vol. 65, no. 10, pp. 8101-8111, Oct. 2018.

[3] K. Fujii, P. Koellensperger, and R. De Doncker, "Characterization and comparison of high blocking voltage igbts and iegts under hardand soft-switching conditions," IEEE Trans. Power Electron., vol. 23, no. 1, pp. $172-179$, Jan. 2008.

[4] L. F. Costa, S. A. Mussa, and I. Barbi, "Multilevel buck/boost-type DC-DC converter for high-power and high-voltage application," IEEE Trans. Ind. Appl., vol. 50, no. 6, pp. 3931-3942, Nov. /Dec. 2014.
[5] K. Filsoof and P. W. Lehn, "A bidirectional multiple-input multipleoutput modular multilevel DC-DC converter and its control design," IEEE Trans. Power Electron., vol. 31, no. 4, pp. 2767-2779, 2016.

[6] H. Al-Atrash, F. Tian, and I. Batarseh, "Tri-modal half-bridge converter topology for three-port interface," IEEE Trans. Power Electron., vol. 22, no. 1, pp. 341-345, Jan. 2007. 